\title{
O papel do psicólogo no programa de implante coclear do Hospital de Reabilitação de Anomalias Craniofaciais
}

\author{
The psychologist's role in the cochlear implant program from the \\ Hospital de Reabilitação de Anomalias Craniofaciais
}

\author{
Midori Otake YAMADA \\ Maria Cecília BEVILACQUA²
}

\begin{abstract}
Resumo
O objetivo deste trabalho é relatar o papel do psicólogo no programa de implante coclear do Hospital de Reabilitação de Anomalias Craniofaciais da Universidade de São Paulo, Bauru, desenvolvido por uma equipe interdisciplinar para a reabilitação de pessoas com deficiência auditiva. O trabalho do psicólogo envolve as seguintes etapas: estudo de caso, preparação pré-cirúrgica, acompanhamento pós-cirúrgico e acompanhamento na reabilitação. Os quatro momentos são permeados pelo contínuo trabalho em relação aos sentimentos do paciente, relação familiar e pela investigação sobre a mudança ocorrida na sua vida e na da família durante o processo.
\end{abstract}

Palavras-chave: psicologo; deficiente auditivo; implante coclear; surdez.

\begin{abstract}
The purpose of this paper is to report the psychologist's role on the Cochlear Implant Program at the Hospital de Reabilitação de Anomalias Craniofaciais, Universidade de São Paulo, Bauru, developed by an interdisciplinary team focused on hearing impairment patients' rehabilitation. The psychologist's responsibilities are:case study, pre-surgical case, post-surgical management and rehabilitation follow-up. These four stages are permeated by a continuous task that concerns the patients'feelings, familiar relations and a careful investigation about the changes occurred in their and their families lives throughout this process.
\end{abstract}

Key words: psychologist; aurally disabled; cochlearimplants; deaf.

O presente estudo é fruto da experiência das autoras com pessoas com deficiência auditiva profunda e seus familiares, que buscam atendimento no Programa de Implante Coclear (PIC) do Centro de Pesquisas Audiológicas (CPA), do Hospital de Reabilitação das Anomalias Craniofaciais da Universidade de São Paulo (HRAC-USP), em Bauru, SP, desde 1990.
O CPA, além de oferecer atendimento às pessoas com deficiência auditiva, tem como objetivos formar docentes e pesquisadores na área da ciência da audição, assessorar outros setores do hospital, o curso de pós-graduação e outros centros audiológicos e de serviços públicos de diferentes regiões do país.

$\nabla \nabla \nabla \nabla \nabla$

1 Centro de Pesquisas Audiológicas, Hospital de Reabilitação das Anomalias Craniofaciais, Universidade de São Paulo. Caixa Postal 620, 17043-900, Bauru, SP, Brasil. Correspondência para/Correspondence to: M.O. YAMADA. E-mail:<midoriotake@yahoo.com.br>, <miotake@centrinho.usp.br>.

2 Departamento de Fonoaudiologia, Faculdade de Odontologia de Bauru, Universidade de São Paulo. Bauru, SP, Brasil. 
Considerado pioneiro no Brasil, o PIC tem feito com que outros programas - que se constituíram ou que estão se constituindo em outros estados - procurem por sua assessoria, motivando a elaboração deste artigo como uma das alternativas de contribuição para as novas equipes.

O PIC tem características próprias, oferece uma estrutura de trabalho de equipe interdisciplinar e compartilha com a filosofia de humanização no hospital. A proposta da equipe que o desenvolve é ver o paciente na sua totalidade, como um ser integrado no mundo, e não focado na sua surdez.

Cabe, neste momento, destacar que a indicação de um implante coclear (IC) tem critérios muito bem definidos: destina-se exclusivamente àquelas pessoas com deficiência auditiva profunda e que não obtêm benefícios com o uso do aparelho de amplificação sonora individual (AASI).

O IC é um dispositivo eletrônico designado a prover a audição e melhorar a comunicação de pessoas incapazes de compreender a fala por meio do AASI. É composto por uma parte interna, implantada mediante intervenção cirúrgica, sendo os eletrodos inseridos na cóclea. A parte externa, por intermédio de um microfone instalado junto à orelha, capta o som que é transmitido por um fio ao processador de fala. O processador envia a informação codificada para uma antena transmissora colocada junto ao receptor-estimulador. O ciclo da audição se completa quando o estímulo elétrico e os sinais codificados são transmitidos por radiofreqüência para o receptor-transmissor. Esse aparelho estimula os eletrodos que são implantados na cóclea (Costa Filho, Bevilacqua \& Moreti, 1996; Costa Filho, Bevilacqua, Amantini \& Lamônica Neto, 2002).

Cada pessoa e cada família vivencia a surdez de modo singular. Assim, o benefício do IC depende também dos objetivos e das possibilidades físicas, emocionais e sociais de cada pessoa, bem como das expectativas familiares. A percepção da qualidade do som captado pelo IC é um aspecto que deverá ser exaustivamente explorado antes da cirurgia, pois o implantado deverá ter a exata noção de que jamais ouvirá novamente como quando tinha a audição perfeita. O som obtido com o IC, embora melhore a comunicação e a percepção sonora, é muito diferente do que o ouvido humano naturalmente capta.
Considerando os problemas emocionais relacionados à surdez, à cirurgia e ao IC, a intervenção do psicólogo é fundamental no trabalho com o paciente, com a família e, conseqüentemente, com a equipe.

O presente trabalho é um estudo descritivo e tem por objetivo relatar o papel do psicólogo no PIC do HRAC, USP, Bauru. De acordo com Triviños (1992), o relato de experiência profissional tem por objetivo aprofundar a descrição de determinada realidade - no caso deste trabalho, o cotidiano do psicólogo.

Este trabalho tem ainda o objetivo de estimular o intercâmbio de conhecimentos, olhares e experiências entre equipes, profissionais e pessoas ligadas à área para uma ação coletiva mais global, bem como colaborar com pesquisas que busquem a humanização no atendimento.

\section{Relato de Experiência}

Dentro do PIC, a atuação do psicólogo se dá segundo as etapas que o paciente realiza no programa: inicia-se com o estudo de caso, realizado em conjunto com a equipe e perdura por todo o processo de reabilitação e acompanhamento vitalício.

Faz parte do trabalho do psicólogo: 1) estudo de caso/avaliação psicológica; 2) preparação pré-cirúrgica; processo de decisão; internação; 3) acompanhamento pós-cirúrgico; na internação; nas primeiras ativações do implante coclear; 4) acompanhamento na reabilitação.

Esses quatro momentos são permeados pelo contínuo trabalho com os sentimentos do paciente e com a família e pela investigação das mudanças ocorridas na sua vida e na vida da família durante todo o processo.

Partindo da perspectiva de que a Psicologia Existencial é a ciência que estuda o ser do homem, é fundamental que se conheça sobre seu vivenciar e experienciar, razão pela qual, neste trabalho, serão abordadas as experiências da pessoa com surdez e com o IC durante seu processo de reabilitação.

A proposta inicial do trabalho do psicólogo no PIC é acolher a pessoa em todo o seu "ser": paciente e família são ouvidos e aceitos para que possam contar com o apoio dos profissionais. Concomitantemente a 
esse processo de acolhida, há o atendimento de outros profissionais.

\section{Avaliação psicológica}

Para conhecer o paciente e sua família, são realizadas sessões que têm por objetivo a exploração e o conhecimento do mundo interno da pessoa e do funcionamento do sistema familiar. Para tal, utiliza-se, basicamente, a entrevista psicológica e alguns instrumentos auxiliares, como testagens e outras técnicas que se fizerem necessárias. Os procedimentos diferenciam-se de acordo com a idade do paciente.

No caso de adultos, a ênfase é colocada na vivência do entrevistado, sempre com o objetivo de conhecer e compreender sua experiência para se ter uma visão global da pessoa desde os aspectos mentais até os psicodinâmicos. Mediante a descrição do mundo próprio do sujeito e de sua situação atual, o psicólogo procura apreendê-lo em sua totalidade. A avaliação psicológica procura identificar em que ponto de sua existência o sujeito se encontra e que significados ele constrói em si e no mundo (Augras, 2000).

Além de uma atitude receptiva, é necessário que o entrevistador observe e avalie criticamente, segundo sua experiência clínica e conhecimento teórico, o que ocorre durante a entrevista. Assim, são formuladas hipóteses que serão testadas ao longo das entrevistas futuras, sempre com o objetivo de entender o caso (Cunha, 1993).

Dessa maneira, é necessário conhecer a história do paciente, a sua experiência com a surdez e suas expectativas e motivações quanto ao implante coclear.

Algumas técnicas, como desenho e/ou pintura, podem ser utilizadas para favorecer a expressão de sentimentos e possibilitam verificar a criatividade e conhecer o mundo interno da pessoa. É preciso lembrar também que, dentro do processo de estudo de caso, o conhecimento da psicopatologia se faz necessário.

As entrevistas com os familiares são realizadas para conhecer a dinâmica familiar e a entrevista psicológica com pessoas com deficiência auditiva tem um caráter especial e exige cuidado e habilidade do psicólogo na escolha das técnicas que serão utilizadas para favorecer a comunicação e incentivar a colaboração do paciente para expressar seus sentimentos, visto que ele tem necessidades especiais. Assim, é muito importante que o psicólogo esteja atento e perceba qual o melhor canal de comunicação em cada situação.

No caso da criança, o estudo depende dos pais e de outros órgãos envolvidos na sua reabilitação (escola, fonoaudiólogos e outros) e que contribuem para a análise e compreensão do caso ao trazerem informações. Dependendo da idade da criança, da perda auditiva, da facilidade na comunicação e da sua cooperação, ela pode ser submetida a uma entrevista ou ser avaliada por intermédio de jogos (hora de jogo).

Segundo Cunha (1993), muitos fenômenos podem ser observados por meio das brincadeiras da criança: podem avaliar inteligência, criatividade, espontaneidade, habilidades perceptomotoras, processos de pensamento, percepção de si e dos outros.

Segundo Trinca (1984), na hora de jogo avalia-se tanto o aspecto evolutivo como psicopatológico, além da capacidade adaptativa e simbólica da criança.

Quando a criança faz uso da comunicação verbal - dependendo de sua idade -, a entrevista é utilizada para uma "conversa", investigando-se a criança, sua relação com a família e com a deficiência auditiva, ou até mesmo suas expectativas sobre o implante coclear. Utiliza-se a psicometria para uma estimativa do nível intelectual e para a avaliação da personalidade, instrumento de auxílio no diagnóstico diferencial da deficiência auditiva.

O estudo da dinâmica familiar se faz necessário porque a reabilitação da criança depende do envolvimento familiar. Embora todos os membros da família passem por momentos de tensão, a mãe, especialmente, pelo papel e funções que desempenha, fica sobrecarregada e mais exposta ao estresse. A busca da recuperação do equilíbrio familiar é necessária para viabilizar e otimizar o desenvolvimento da criança (Matsukura, Emmel, Palhares, Matinez \& Surrian, 2000).

Sendo assim, a importância da família no desenvolvimento global da criança é inegável: é por intermédio dela que a criança aprende e forma sua visão de mundo, pois o modo como a família lida com a questão da deficiência auditiva interfere na sua vivência com a deficiência.

Vários são os estudos que relatam a importância da família na reabilitação da criança com deficiência 
auditiva (Almeida, 1991; Carvalho, 1992; Pereira \& Carvalho, 1993; Harrison, 1994; Vasconcelos \& Botelho, 1995; Martins, Borges \& Yazigi, 1996; Yamada, 1998; Silva, Krom, Bevilacqua \& Yamada, 1999; Yamada, Bevilacqua \& Costa Filho, 1999; Motti \& Pardo, 2002). Sendo assim, é muito importante conhecer cada família, sua estrutura e funcionamento, verificar como os membros vivenciam a questão da deficiência auditiva, as expectativas do atendimento da instituição e do IC.

No estudo de caso, os limites entre a avaliação psicológica e a intervenção terapêutica ficam diluídos. Esse processo pode auxiliar a equipe, o próprio sujeito - na compreensão de si mesmo - e a família na reconstrução de novas possibilidades do funcionamento do sistema familiar.

Geralmente existe a necessidade de orientar o paciente e a família sobre as habilidades e potencialidades que possuem para se reorganizarem, assim, faz-se o encaminhamento para a psicoterapia, se necessário.

Os critérios de elegibilidade para o PIC/HRAC/ USP-Bauru estão relacionados a aspectos médicos, audiológicos, psicológicos ou sociais. No aspecto psicológico, não é considerado elegível para o programa, no momento, pacientes com distúrbios mentais de qualquer natureza mais grave (deficiência mental, psicose ou outras psicopatologias). Embora não seja um critério de exclusão, o estado emocional do paciente e da família também devem ser considerados: a pessoa ou a família pode estar desestruturada por ter recebido o diagnóstico da deficiência auditiva ou estar num momento crítico por alguma razão, no entanto, dependendo da causa, esse estado pode ser alterado. Ou seja, pode não ser favorável para o programa de implante num momento e ser no outro (Bevilacqua, Costa Filho \& Moret, 2002; Costa Filho et al., 2002). Assim, o trabalho de aconselhamento da equipe de psicólogos e de outros profissionais engajados na reabilitação do paciente bem como o contato com outros pacientes implantados e familiares são de grande importância e extremamente necessários.

\section{Preparação pré-cirúrgica}

\section{Primeira etapa: processo de decisão}

Esta fase ocorre em continuidade ao processo de avaliação e o atendimento pode ser individual ou familiar. É nela que se delibera sobre realizar ou não o IC, podendo ser um período conflituoso tanto para o paciente como para a família, sendo fundamental a intervenção do psicólogo. O IC é uma alternativa; a escolha torna-se difícil e gera conflito interno, especialmente quando as expectativas são altas e não condizentes com a realidade. Nessa etapa, os riscos de uma cirurgia e o aspecto visível da unidade externa do IC são fatores exaustivamente considerados.

Nesse processo, cabe ao psicólogo, ainda, refletir sobre outras interferências que possam surgir, como a própria relação psicólogo-paciente, equipe-paciente, família-paciente e outras.

No caso da criança, além das entrevistas, utiliza-se material lúdico no preparo pré-cirúrgico, tais como bonecas, brinquedos relacionados aos objetos hospitalares, como estetoscópio, seringas, gaze, réplica da unidade externa do IC, play-mobil hospital etc.

Uma cirurgia traz, para a criança, situações com as quais ela não está acostumada. Pessoas estranhas, injeções, ambiente desconhecido e procedimentos dolorosos contribuem para provocar reações de insegurança e medo de todo esse desconhecido. Sendo assim, é de fundamental importância que a criança seja devidamente preparada a fim de que os processos psicológicos desencadeados pela situação não comprometam a própria recuperação do paciente (Ferrari, 1985).

Durante essa etapa é oferecido um espaço para que a criança possa se familiarizar e dramatizar situações que irá vivenciar no processo cirúrgico: contato com materiais hospitalares, dramatização do corte de cabelo (que é necessário nesse tipo de cirurgia), curativos e vivência da situação hospitalar através de diversos brinquedos.

A intervenção psicológica se dá de acordo com a faixa etária do paciente e a necessidade de cada caso. É importante ressaltar que a vivência se torna fundamental para a criança com deficiência auditiva, porque ela perde as informações do meio e os acontecimentos para ela são repentinos e abruptos, contribuindo para reações de susto e medo do desconhecido (Yamada et al., 1999).

\section{Segunda etapa: internação}

No período de internação, novamente, podem surgir necessidades de se trabalhar com a pessoa/família 
no que se refere à ansiedade, ao medo, à angústia, aos sentimentos comuns frente à cirurgia. É quando o psicólogo ouve, acolhe, discute os sentimentos, desmistifica as fantasias e convive com a ansiedade e a angústia juntamente com todos. É seu papel acompanhar o paciente durante a internação para maior compreensão dos acontecimentos ao seu redor, e retomar o contato antes da cirurgia, na sala de pré-operatório, a fim de tranqüilizá-lo.

Para a criança, a situação de hospitalização pode ser nova, ocasião em que sentimentos como o temor do desconhecido é maior. Com medo, ela vai explorando e descobrindo a nova situação, e a equipe do hospital age minimizando esse fator. O processo pode ser mais ameno ou não dependendo das experiências anteriores de hospitalização (Yamada et al., 1999).

A sala de pré-operatório oferece um clima mais tranqüilo e menos ameaçador, pois nela a criança tem alguns brinquedos à disposição.

\section{Acompanhamento pós-cirúrgico}

\section{Na internação}

Nessa etapa, o trabalho é focado no período de recuperação. São trabalhados as verbalizações e sentimentos do paciente, favorecendo sua recuperação do ponto de vista psicológico. O psicólogo trabalha as questões que surgem: a vergonha que o paciente sente por estar com uma parte da cabeça raspada, a sua imagem corporal no relacionamento com o outro, a saída do ambiente natural, ou seja, o afastamento da família e do trabalho, a dinâmica da deficiência auditiva em sua vida e/ou a vivência familiar, que apresentam necessidade de elaboração. Também é trabalhada a alta, dando-se atenção ao retorno ao cotidiano, preparando o paciente para uma nova etapa. Assim, procura-se observar as expectativas e atitudes do paciente e da família, buscando desmistificar alguns aspectos da dinâmica limite-possibilidade.

No caso da criança, são oferecidos brinquedos, solicitados desenhos e trabalha-se novamente com os objetos lúdicos do preparo pré-operatório, para que a criança possa vivenciar e elaborar sua situação e seu contexto.

\section{Nas primeiras ativações do implante coclear}

As primeiras ativações do $I C$, até mais ou menos seis meses após a cirurgia, iniciam a fase de adaptação do IC - para o paciente e para a família.

Inicialmente, com muita emoção, a pessoa é afetada pelo impacto de estar ouvindo. A emoção é perturbadora positiva ou negativamente. Posteriormente, ocorre um período de sentimentos confusos e, em certos momentos, ambivalentes. Nesse período, a pessoa pode ficar perturbada e angustiada, ocasião em que a realidade e a fantasia do processo ouvir se misturam, sendo de grande valia a ajuda emocional proporcionada pelo psicólogo.

No caso da criança, podem ocorrer dificuldades tanto para ela, na adaptação ao uso da unidade externa do IC, quanto para a família, com a nova situação vivenciada por todos: angústia e desespero pela possibilidade de a criança não aceitar o IC; excesso de cuidados dos pais para com o IC e com a criança, somado à superproteção - que geralmente já ocorria antes; ansiedade quanto ao resultado do implante e, conseqüentemente, com a fala da criança. É uma fase de readaptação do paciente e da família para uma nova realidade.

Nesse período, além dos atendimentos individuais, inicia-se o trabalho de grupo de pacientes e familiares, o que proporciona trocas de experiências e ajuda mútua entre os membros, trabalhando-se as questões surgidas durante as conversas.

O grupo é aberto e formado pelos pacientes com retorno agendado para o mapeamento do seu IC e atendimento pela equipe interdisciplinar. $O$ grupo de adultos é composto em média por três elementos, de maneira a permitir melhor comunicação e, em alguns casos, existir a necessidade de leitura orofacial (LOF). O grupo de família dos pacientes adultos é formado somente quando há, no mínimo, a presença de membros de duas famílias.

O grupo das crianças implantadas forma-se concomitantemente ao grupo dos pais/familiares. Cada encontro é único e depende do agendamento de retorno. Mediante uma leitura sistêmico-existencial, o psicólogo trabalha os conteúdos emergentes no grupo 
e auxilia na construção e reconstrução das novas possibilidades vivenciais.

\section{Acompanhamento da reabilitação}

O acompanhamento, na reabilitação, é feito nos atendimentos de retorno, após seis meses de uso do IC. Nesse período, continua-se trabalhando o conteúdo que o paciente e a família trazem, com especial atenção para as particularidades de cada caso, e investigam-se as mudanças ocorridas na vida do paciente e da família após oIC.

\section{Considerações}

Levando-se em conta as etapas do processo de atuação do psicólogo, é possível perceber que os pacientes e seus familiares também constroem seus caminhos em etapas. De início, tanto o paciente como a família se apresentam com idéias fantasiosas em relação ao IC, expectativas altas e ansiedade frente à nova situação. Seus sentimentos são confusos e angustiados; demonstram uma atitude de passividade ou de resistência em relação ao psicólogo, e posteriormente vão se tornando mais abertos, conscientes e participativos.

Pela própria limitação que a deficiência auditiva provoca na comunicação, algumas entrevistas podem se tornar desgastantes tanto para o paciente quanto para o profissional. Ocorrem dificuldades para entender a pessoa, bem como de fazer-se entender por ela.

Na prática, em alguns casos, a comunicação verbal é suficiente (sempre com o cuidado especial com a deficiência auditiva). Em outros, é preciso utilizar como auxílio a escrita, o desenho, os gestos e/ou a participação de outros membros da família.

A experiência da surdez para os pacientes e familiares tem um impacto avassalador, alterando todo o ser da pessoa, as relações familiares e a interação com o outro e com o mundo.

No caso da surdez adquirida, a pessoa vivencia a perda e o desamparo. Há um predomínio dos sentimentos negativos, uma tendência ao negativismo, caracterizando um clima afetivo de tensão e depressão. Como parte do enfrentamento da perda, ela passa por um processo de luto, amplamente conhecido nos trabalhos de Kübler-Ross (1987).

Nos pacientes com surdez congênita - a maioria das crianças atendidas neste programa -, o prejuízo auditivo faz parte de sua identidade. Luto, depressão e ansiedade são sentimentos experimentados pelos pais.

Assim, a primeira fase do processo de IC proporciona ao paciente e seus familiares entrarem em contato com as dimensões do mundo do silêncio, o que às vezes era evitado para não entrar em contato com o sofrimento e com a dor.

Os pacientes e familiares manifestam os sentimentos e permitem-se ressignificar a surdez. Percebem com maior segurança a parcela de responsabilidade frente à realidade e adquirem uma postura mais aberta para novas possibilidades, tanto individuais como familiares.

Por meio da análise existencial o paciente faz um exame da própria vida e a função do psicólogo é criar condições facilitadoras para que ele elabore e compreenda por si mesmo todo o processo pelo qual está passando e passará, obtendo assim esclarecimentos e delimitando suas expectativas.

No processo da tomada de decisão de fazer ou não a cirurgia de IC, a pessoa quer voltar a ouvir, e esse querer está relacionado ao desejo de ouvir como antes (quando ouvinte), o que não é possível. Tendo em vista que, no desejo, o emocional é mais presente que o racional (incluindo valores, crenças e fantasias), sempre há dificuldade em lidar com essa realidade. Ao mesmo tempo em que deseja realizar o IC, que possibilitará mudanças no seu "ser-não-ouvinte", existe a possibilidade de permanecer como está, sem correr riscos.

Destaca-se, assim, a importância da atuação do psicólogo junto ao paciente e à família no momento de lidarem com essa realidade, pois chegam com expectativas altas e informações distorcidas sobre o implante, aspectos somados às dificuldades individuais de cada caso.

O trabalho psicológico proporciona-lhes conscientização, responsabilidade e liberdade na tomada de decisão quanto à realização ou não da cirurgia e possibilita-Ihes trabalhar sentimentos e emoções que precisam ser elaborados. Para Romero 
(1999), tais aspectos são fundamentais na intervenção psicológica.

As crianças também podem vivenciar situações hospitalares, brincar e expressar-se, o que é saudável do ponto de vista emocional.

No pós-cirúrgico, quase sempre existe um misto de alívio e apreensão. De um lado, alívio porque a situação tida como a mais delicada (a cirurgia) foi superada; de outro, apreensão, pela preocupação com a recuperação, com os cuidados necessários e com o que está por vir.

Segundo Angerami, Maciel, Maia, Pérez-Ramos, Roth e Campos, (2002), a filosofia de humanização nas relações mobiliza o paciente a colaborar com o tratamento, fortalecendo-o para lidar com a situação de crise e amenizar o processo de internação.

O psicólogo é um elemento voltado à atenção afetiva, é aquele que ouve o outro lado das queixas do paciente e seus posicionamentos sem estar voltado ao tratamento clínico médico, e auxilia também na redução do stress pré-e pós-operatório.

No decorrer da fase pós-cirúrgica e na reabilitação, as vivências emocionais marcantes dos pacientes são: o impacto de ouvir, a fase de adaptação com o implante tanto por parte do paciente como por parte da família e o novo "ser ouvinte". O impacto de estar ouvindo é sempre uma experiência de muita emoção e de realização, após a experiência angustiante da surdez.

Na fase de adaptação, o paciente pode vivenciar sentimentos contrários e até ambivalentes. Alegria por ouvir e tristeza por não compreender a fala do outro. Satisfação pelos benefícios do IC e sentimento de incômodo pela aparência da unidade externa. A adaptação dos familiares quanto ao modo de se comunicar é determinante, pois, nesse momento, de qualquer maneira, a pessoa já está ouvindo.

O terceiro momento caracteriza-se pela integração do "ser surdo" e do "ser ouvinte". Significa que a pessoa continua tendo a deficiência auditiva e também a audição. Para essas pessoas, a experiência com o IC significa o resgate da confiança perdida, a possibilidade de diálogo, de fazer planos para o futuro e de se relacionar de maneira mais completa.
Durante todas as etapas vivenciadas pelos pacientes e familiares, os sentimentos e as emoções predominantes são a ansiedade, a angústia, o medo, a tristeza, a alegria e a tranqüilidade; sentimentos mais fortes em alguns momentos e mais amenos em outros, revelando a força e a presença da afetividade ou dimensão afetiva na vida da pessoa (Yamada, 2002).

Com o IC, muitos pacientes relatam melhoras na comunicação, conseqüentemente, diminuição do stress, melhora na qualidade de vida e percepção mais positiva da realidade vivenciada. Yamada (2002) também constatou em seu estudo que após o uso do IC acontecem mudanças positivas nos sentimentos e estados de ânimo dos implantados, tendo observado uma avaliação positiva e de sintonia com o mundo.

No caso das crianças, os relatos mais freqüentes dos pais são a respeito das melhoras na audição e na fala da criança, conseqüentemente, passa a existir uma melhor comunicação entre pais e filhos; há a percepção de que a criança ficou mais calma e os pais experienciam sentimentos de satisfação e tranqüilidade, com diminuição da ansiedade e insegurança.

\section{Conclusão}

Diante do contexto apresentado, conclui-se que a atuação do psicólogo no processo de IC torna-se abrangente ao lidar com o paciente, a família e a equipe multiprofissional:

- sua atuação junto ao paciente é fundamental em todas as etapas do programa, pois o ajuda a elaborar suas questões emocionais, compreendendo seu mundo e dando-Ihe suporte durante todo o processo do programa;

- tendo em vista que a família do paciente é um microcosmo, quando um membro é afetado todos os outros também o são, assim, o suporte psicológico familiar se faz necessário, auxiliando na construção de novas realidades;

- o trabalho em equipe é fundamental e o paciente deve ser considerado na sua totalidade, aspecto que deve estar presente especialmente na construção da atitude interdisciplinar de todos os profissionais que lidam com ele. 


\section{Referências}

Almeida, E.C. (1991). Grupo de mães de crianças deficientes auditivas: o impacto do diagnóstico. Distúrbios da Comunicação, 4 (2), 199-209.

Angerami, V.A., Maciel, S.C., Maia, E.M.C., Pérez-Ramos, A.M.Q., Roth, M.C., \& Campos, T.C.P. (2002). Novos rumos na psicologia da saúde. São Paulo: Pioneira Thomson Learning. 187p.

Augras, M. (2000). O ser da compreensão: fenomenologia da situação de psicodiagnóstico (9.ed.). Petrópolis: Vozes. 96p.

Bevilacqua, M.C., Costa Filho, O.A., \& Moret, A.L.M. (2002). Implante coclear em crianças. In C.A.H. Campos \& H.O.O Costa. Tratado de otorrinolaringologia (pp. 269-277). São Paulo: Roca.

Carvalho, J.M. (1992). O trabalho do psicólogo na escola especial com grupo de orientação aos pais de crianças deficientes auditivas. Distúrbios da Comunicação, 5 (1), 59-68.

Costa Filho, O.A., Bevilacqua, M.C., \& Moreti, A.L.M. (1996). Critérios de seleção de crianças candidatas ao implante coclear do Hospital de Pesquisa e Reabilitação de Lesões Lábio Palatais - USP. Revista Brasileira Otorrinolaringologia, 62 (4), 306-313.

Costa Filho, O.A., Bevilacqua, M.C., Amantini, R.C.B., \& Lamônica Neto, D. (2002). Implante coclear em adultos. In C.A.H. Campos, H.O.O. Costa. Tratado de otorrinolaringologia (pp.278-289). São Paulo: Roca.

Cunha, J.A. (1993). Psicodiagnóstico (4. ed.). Porto Alegre: Artes Médicas. 533p.

Ferrari, B. (1985). Preparação psicológica do paciente cirúrgico. Doutora, 2 (7), 47-50.

Harrison, K.M.P. (1994). A surdez na família: uma análise de depoimentos de pais e mães. Dissertação de mestrado em Distúrbios da Comunicação não-publicada, Pontifícia Universidade Católica de São Paulo.

Kübler-Ross, E. (1987). Sobre a morte e o morrer (3.ed.). São Paulo: Martins Fontes. 290p.

Martins, M.C.F.N., Borges, A.C.L.C., \& Yazigi, L. (1996). Aconselhamento de pais de crianças deficientes auditivas: aspectos psicológicos. Pró-Fono, 8 (1), 19-24.
Matsukura, T.S., Emmel, M.L.G., Palhares, M.S., Matinez, C.M.S., \& Surrian, C.E. (2000). A importância da previsão de suporte aos cuidados de crianças portadoras de transtornos no desenvolvimento. Temas sobre Desenvolvimento, 8 (48), 5-10.

Motti, T.F.G., \& Pardo, M.B.L. (2002). Diagnóstico da deficiência auditiva: compreensão dos pais e seguimento às orientações. Acta AWHO,21 (1) [online serial]. Disponível em: <http://www.actaawho.com.br>. Acesso em: 29 nov. 2002.

Pereira, M.C.C., \& Carvalho, J.M. (1993). O trabalho em grupo com pais de crianças deficientes auditivas. Distúrbios da Comumicação, 6 (1), 77-82.

Romero, E. (1999). Neogênese: o desenvolvimento pessoal mediante a psicoterapia. São José dos Campos: Novos Horizontes. $351 \mathrm{p}$.

Silva, S.C., Krom, M., Bevilacqua, M.C., \& Yamada, M.O. (1999). Família da criança deficiente auditiva: características e recursos. Pró-Fono, 11 (1), 47-52.

Trinca, W. (1984). Diagnóstico psicológico: prática clínica. São Paulo: EPU. 106p.

Triviños, A.N.S. (1992). Introdução à pesquisa em ciências sociais: a pesquisa qualitativa em educação. São Paulo: Atlas. $175 \mathrm{p}$.

Vasconcelos, L.G.E., \& Botelho, A.C.M.M. (1995). Orientação a pais de crianças com distúrbios de comunicação: relato de experiência. Pró-Fono, 7 (1), 16-20.

Yamada, M.O. (1998). A construção da deficiência auditiva na família. Monografia de Especialização em Terapia Familiar e de Casal não-publicada, Instituto Bauruense de Psicodrama, Bauru.

Yamada, M.O. (2002). Dimensão afetiva, segundo a concepção de Emílio Romero, da pessoa com surdez adquirida antes e após o uso de implante coclear. Dissertação de mestrado em Distúrbios da Comunicação Humana não-publicada, Hospital de Reabilitação de Anomalias Craniofaciais, Universidade de São Paulo, Bauru.

Yamada, M.O., Bevilacqua, M.C., \& Costa Filho, O.A. (1999). A intervenção do psicólogo no pré e pós operatório do programa de implante coclear. Pediatria Moderna, 35 (3), 92-96.

Recebido para publicação em 1 de março de 2004 e aceito em 20 de abril de 2005. 